\title{
Erratum
}

Fresenius J Anal Chem (1993) 345:547-563

\section{On-line coupling of atomic spectrometry and ion chromatography with time resolved registration as a new tool for ultra trace analysis in refractory metals}

\author{
A. Seubert \\ Institut für Anorganische Chemie, Universität Hannover, Callinstrasse 9, D-30167 Hannover, Germany \\ Received July 2, 1992; revised October 2, 1992
}

In Table 3 on page 549 the column headings were unfortunately omitted. The entire table is printed correctly below.

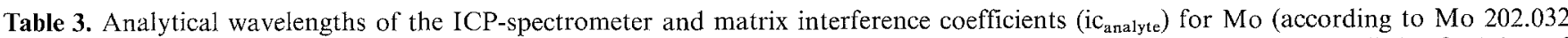
$\mathrm{nm}$ ) and W (according to the interference signal at the Se $196.09 \mathrm{~nm}$ line). The peak area calibration factor $\mathrm{f}_{\mathrm{A}}$ was $3.03 \mathrm{dig} / \mathrm{ng}$ for $\mathrm{Mo}$ and $0.069 \mathrm{dig} / \mathrm{ng}$ for $\mathrm{W}$. All data were evaluated with $1.85 \mathrm{ml} / \mathrm{min}$ sample flow rate and $10 \mathrm{~s}$ integration time. The signal to background ratios $I_{n} / I_{b}$ and the estimated L.D. were calculated in the way described in [18]

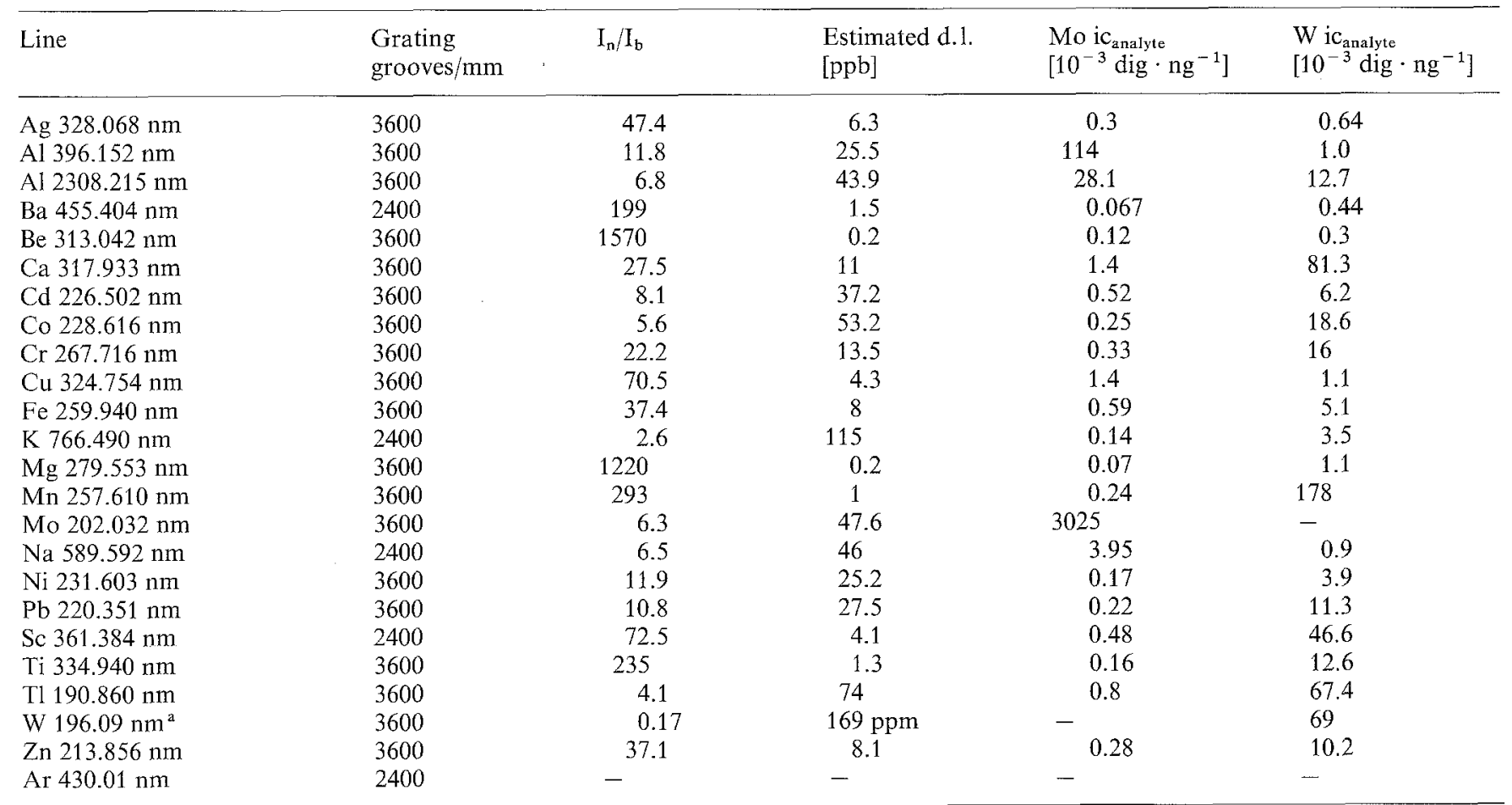

a As monitor for $\mathrm{W}$ the interference of the W $196.149 \mathrm{~nm}$ line at the Se $196.09 \mathrm{~nm}$ line was used, the signal to background ratio was measured with a $1000 \mathrm{ppm} \mathrm{W}$ solution 